\title{
Prevalence of Burnout among Primary Health Care Staff and Its Predictors: A Study in Iran
}

\author{
Ehsan Zarei ${ }^{1}$, Fariba Ahmadi ${ }^{2}$, Muhammad Safdar Sial ${ }^{3}$, Jinsoo Hwang ${ }^{4, *}$, Phung Anh Thu ${ }^{5, *}$ \\ and Sardar Muhammad Usman ${ }^{3}$ \\ 1 Department of Health Services Management, School of Management and Medical Education, \\ Shahid Beheshti University of Medical Sciences, Tehran, Iran; zarei_1980@yahoo.com \\ 2 Deputy of Health Affairs, Kermanshah University of Medical Sciences, Kermanshah, Iran; \\ afariba18318@yahoo.com \\ 3 Department of Management Sciences, COMSATS University Islamabad (CUI), Islamabad 44000, Pakistan; \\ safdarsial@comsats.edu.pk (M.S.S.); susman@comsats.edu.pk (S.M.U.) \\ 4 The College of Hospitality and Tourism Management, Sejong University, 98 Gunja-Dong, Gwanjin-Gu, \\ Seoul 143-747, Korea \\ 5 Faculty of Finance and Accounting, Nguyen Tat Thanh University, Ho Chi Minh City 700000, Vietnam \\ * Correspondence: jhwang@sejong.ac.kr (J.H.); pathu@ntt.edu.vn (P.A.T.)
}

Received: 2 June 2019; Accepted: 22 June 2019; Published: 25 June 2019

\begin{abstract}
Burnout, which is an emerging challenge in health systems, is very common among primary health care (PHC) workers. The aim of this study was to investigate the level of burnout among PHC workers, and its predictive factors, in a region in the west of Iran. In this cross-sectional study, all the health network staff $(n=539)$ were enrolled. The data collection instrument was the Maslach Burnout Inventory (MBI), which consists of 22 items and the three subscales of emotional exhaustion (EE), depersonalization (DP), and personal achievement (PA). High scores in EE and DP and low scores in PA are indicative of high burnout. Logistic regression was used to determine the predictors of high burnout. The data were analyzed using SPSS version 16 . The findings showed that $90.5 \%$ of the staff had high DP, 55.3\% had high EE, and 98.9\% had low PA scores. Also, 52.9\% (277 people) of the staff suffered from high burnout. Single people $(\mathrm{OR}=3.33)$, less experienced employees $(\mathrm{OR}=9.09)$, people aged over 35 years $(\mathrm{OR}=2.35)$, physicians $(\mathrm{OR}=1.72)$, and staff with permanent employment $(\mathrm{OR}=5.0)$ were more likely to suffer high levels of burnout. We conclude that burnout is a common problem in PHC workers. Less experienced, younger, single employees and physicians were more at risk of suffering from high burnout. Preventive measures, such as strengthening social skills, communication competencies, and coping strategies, and reduction of risk factors such as job stress, are suggested for reducing employees' risk of burnout.
\end{abstract}

Keywords: burnout; primary health care; occupational health; Iran

\section{Introduction}

Primary health care (PHC) includes providing services for disease prevention, treatment, management and rehabilitation. It is an essential part of the health system in achieving its goal of improving the health of populations [1,2]. A PHC system needs a competent, effective, and motivated workforce to provide high-quality services to meet the stated goal. Notwithstanding this, structural reforms in the health system have led to heavy workloads, which may lead to employees burnout [3]. Health worker' burnout is a considerable challenge for health systems, with potential negative consequences for the health care provider, the patients and the health care organizations [4-9]. For this reason, burnout has attracted considerable research attention in the past two decades, in both developing and developed countries [10,11]. 
Occupational burnout is a psychological state that was first defined by Maslach in the 1980s as the end state of chronic stress associated with work [12]. This condition is composed of emotional exhaustion (EE), depersonalization (DP), and reduced personal achievement (PA). EE refers to the reduction or loss of emotional resources and the feeling of being emotionally exhausted due to work, along with the feeling that there is nothing to offer psychologically to others. DP is negative attitudes and feelings and a lack of sensitivity and empathy towards the people who are being served. Reduced PA is the tendency to assess oneself and one's work negatively, with the avoidance of interpersonal relationships, low productivity, and lack of resistance to stress [13].

Burnout is common among employees who work in stressful environments [4]. Based on the extensive body of evidence available, burnout syndrome is very common in care professions such as healthcare workers [3,7]. Health professionals work in emotional situations and face the physical, economic, social, and psychological problems of patients and their families [14]. They experience a lot of stress due to the need for quick responses to the needs of patients and their families, the high workload, and long hours of work in a complex working environment [13]. Exposure to these conditions can lead to burnout [11]. Recent studies indicate a high level of stress and burnout in healthcare workers. Studies from around the world, including on physicians $[6,15,16]$, nurses $[10,17,18]$, physiotherapists [14-19], primary health care workers [20-22] and other health professionals [4,7,13,23], have reported prevalence rates of burnout from $2.6 \%$ to $75 \%$. In addition, the results of two studies from Iran showed that the prevalence of burnout in PHC workers is $17.3 \%$ to $34.5 \%$ [21,24].

Burnout has serious effects on the physical and mental health of health care providers. Cardiovascular disorders, musculoskeletal disorders, depression, and anxiety are all associated with burnout $[13,25]$. It is also related to absenteeism, low productivity, reduced job satisfaction, and the intention to leave a job. Also, burnout has negative effects on care quality and patient satisfaction $[7,8,16,21,25,26]$. In addition, health system costs increase due to high turnover, absenteeism, reduced staff motivation, poor quality of care, and possible medical errors $[5,8,10,13,16,20]$. Burnout syndrome is the result of the complex interaction of social and individual factors. Job stress, workload, role conflict, organizational changes, and reduced social and organizational support are factors that affect the onset of burnout $[13,25]$. Also, some demographic variables such as age, gender, marital status, educational level, and years of professional experience are assumed to be associated with burnout [26-28].

The study of work issues among health sector employees in Iran has been more focused on hospital staff (especially physicians and nurses) and community health workers have been neglected. Few studies have been performed on burnout among PHC workers in Iran [24-29]. PHC workers perform several tasks and are under great pressure, especially in rural and deprived areas. On the other hand, they have limited career development and opportunity for job promotion [21,30]. In addition, Iran's Health Transformation Plan (HTP) has been under way since 2014. The HTP includes reforms to primary health care, including a non-communicable diseases control plan and implementation of an electronic health record system. This has led to new tasks (in addition to primary tasks) and more expectations of primary health care workers [31], and due to inadequate numbers of primary healthcare workers [30], it has led to an increased workload and stress for them [32]. In the study by Peikan pour et al., job burnout among health staff was identified as one of the weaknesses of the HTP due to the increase in the number of patient visits [33]. On the other hand, in terms of improvements in pay, primary care workers have not been considered, and the focus has been on hospital staff, especially physicians, which has resulted in feelings of inequity and discrimination among community health workers [32-34].

Together, these factors can create the potential for burnout. Therefore, identifying the prevalence of burnout and its predictive factors can help health administrators to develop appropriate preventive interventions. The aim of this study was to examine the level of burnout among PHC workers and its predictive factors in a region in the west of Iran. 


\section{Materials and Methods}

\subsection{Design and Sampling}

This cross-sectional study was conducted in 2018 in a western region of Iran. Based on the structure of the health system in Iran, each county (district) has a health network that provides health services at the primary and secondary levels. Each health network consists of a general district hospital and a set of rural health houses, urban health posts, and urban and rural health centers. Health houses are staffed with community health workers (called "Behvarz", with two years of training undertaken in specialized training centers) and other facilities are staffed with health professionals including: physicians; nurses; midwives; laboratory, radiology and dentistry technicians; and experts on disease control, environmental health, occupational health, mental health, school health, family health and health education [2]. The surveyed health network included 30 rural health houses, five urban health posts, four urban and rural health centers, and one general hospital, which provide services to 71,000 residents. All the health network staff with clinical roles in health services delivery $(n=539)$ were enrolled in the study, and consisted of 267 primary-level and 272 hospital staff. Having at least one year of work experience in the health network was the inclusion criterion of our study.

\subsection{Instrument and Procedure}

The data collection instrument was the Maslach Burnout Inventory (MBI), which is the gold-standard of burnout surveys in the field of medicine [35]. The first part of the questionnaire includes items on demographic variables, and the second part consists of 22 items in the three subscales of emotional exhaustion (EE), depersonalization (DP), and personal achievement (PA). This questionnaire has been used in various studies in Iran to measure burnout, and its Persian translation is available [21]. The Cronbach's alpha coefficient of this questionnaire was calculated at 0.82 , indicating the acceptable internal consistency of the tool.

This questionnaire is rated based on a 7-point Likert scale, ranging from 0 (never) to 6 (every day). Due to the multi-dimensionality of the burnout structure, the scores of each subscale are reported separately and cannot be added up as a total score [36]. According to Maslach, high scores in EE and DP and low scores in PA are considered as high burnout [7,37]. Burnout level is classified into three groups, low, moderate, and high. The cut-off points for this classification [23,37] are presented in Table 1. Questionnaires were distributed in person at the workplace of the staff. After describing the purpose of the study and assuring the confidentiality of information, staff consent to participate in the study was obtained and they were given a week to complete the questionnaire. After a week, completed questionnaires were collected. In total, 524 completed questionnaires we returned (response rate $=97 \%$ ).

Table 1. Classification of burnout level.

\begin{tabular}{lccc}
\hline Level & Low & Moderate & High \\
\hline EE (9 items, 0-54) & $0-18$ & $19-26$ & $27-54$ \\
\hline DP (5 items, 0-30) & $0-5$ & $6-9$ & $10-30$ \\
\hline AP (8 items, 0-48) & $39-48$ & $32-38$ & $0-31$ \\
\hline Note: emotional exhaustion (EE), depersonalization (DP), and personal achievement (PA).
\end{tabular}

\subsection{Data Analysis}

The data were analyzed using SPSS. In the descriptive section, frequency, mean, and standard deviation were used, A $t$-test was also run to compare the mean scores of the burnout subscales in terms of demographic variables. Logistic regression was used to determine the predictors of high burnout with $p$-values less than 0.05 considered statistically significant. 


\subsection{Ethical Considerstions}

This study was approved by the Ethics Committee of Shahid Beheshti University of Medical Sciences (code of ethics: IR.SBMU.PHNS.REC.1397.132). The employees voluntarily participated in the study and their oral consent was obtained before filling in the questionnaire.

\section{Results}

According to the findings, $43 \%$ of the staff were male and $63.4 \%$ had an academic degree. The mean age of the staff was $33.5 \pm 8.3$ years, and the work experience mean was 9 years, which ranged from 1 to 28 years. Also, $12.6 \%$ of the employees were physicians and $60.7 \%$ worked on temporary contracts. In addition, most of the staff (68.5\%) worked in PHC centers (Table 2$)$.

Table 2. Characteristics of the sample $(N=524)$.

\begin{tabular}{llcc}
\hline Variable & & $\mathbf{N}$ & $\mathbf{\%}$ \\
\hline \multirow{2}{*}{ Gender } & Male & 225 & 42.9 \\
\cline { 2 - 4 } & Female & 299 & 57.1 \\
\hline \multirow{2}{*}{ Age } & $35 \leq$ & 338 & 64.5 \\
\cline { 2 - 4 } & $<35$ & 186 & 35.5 \\
\hline \multirow{2}{*}{ Mducation } & Primary & 192 & 36.6 \\
\cline { 2 - 4 } & Academic & 332 & 63.4 \\
\hline \multirow{2}{*}{ Profession } & Single & 189 & 36.1 \\
\cline { 2 - 4 } & Married & 335 & 63.9 \\
\hline \multirow{2}{*}{ Work setting } & Physician & 66 & 12.6 \\
\cline { 2 - 4 } & Non-physician & 458 & 87.4 \\
\hline \multirow{2}{*}{ Work experience } & Health centers & 359 & 68.5 \\
\cline { 2 - 4 } & Hospital & 165 & 31.5 \\
\hline \multirow{2}{*}{ Employment type } & $10 \leq$ & 375 & 71.6 \\
\cline { 2 - 4 } & $<10$ & 149 & 28.4 \\
\hline \multirow{2}{*}{ Permanent } & 206 & 39.3 \\
\cline { 2 - 4 } & Temporary & 318 & 60.7 \\
\hline
\end{tabular}

Table 3 shows the status of burnout. Based on the findings, $90.5 \%$ of staff had high DP, $55.3 \%$ had high EE, and 98.9\% had low PA. According to the classification, $52.9 \%$ ( $n=277$ people) had high burnout (high EE and DP along with low PA).

Table 3. Scores on the MBI subscales.

\begin{tabular}{cccccccc}
\hline \multirow{2}{*}{ MBI Subscale } & \multirow{2}{*}{ Mean \pm SD } & \multicolumn{2}{c}{ Low } & \multicolumn{2}{c}{ Moderate } & \multicolumn{2}{c}{ High } \\
\cline { 3 - 8 } & & $\mathbf{N}$ & $\%$ & $\mathbf{N}$ & $\%$ & N & $\%$ \\
\hline EE (0-54) & $29.68 \pm 8.2$ & 13 & 2.5 & 221 & 42.2 & 290 & 55.3 \\
\hline DP $(0-30)$ & $16.89 \pm 4.8$ & 0 & 0 & 50 & 9.5 & 474 & 90.5 \\
\hline PA (0-48) & $20.92 \pm 5.1$ & 518 & 98.9 & 6 & 1.1 & 0 & 0 \\
\hline
\end{tabular}

Table 4 demonstrates the status of burnout scores in terms of the demographic variables of the employees. Findings showed that, except for the work setting, in all the demographic variableswhich included gender, age, work experience, profession, type of employment, education level, and marital status - the difference in the mean score of EE was significant $(p<0.05)$. EE was significantly 
higher among physicians, female participants, employees under the age of 35 years, employees with fewer than 10 years of work experience, employees with permanent employment, and academic degree holders. The findings showed that the mean score for DP was significantly different based on age, work setting, and marital status $(p<0.05)$. The mean score of DP was higher in single employees, those under the age of 35 years, and employees working in hospitals. The mean score of PA was significantly different based on age, work experience, profession, type of employment, work setting, education level, and marital status ( $p<0.05$ ). The mean score of PA was lower in employees under the age of 35 years, those with less than 10 years of work experience, those with academic degrees, non-physician staff, temporary employees, and staff working in health centers.

Table 4. Comparison of the mean burnout scores in terms of demographic variables.

\begin{tabular}{|c|c|c|c|c|}
\hline \multicolumn{2}{|c|}{ Variable } & EE & DP & PA \\
\hline \multirow{3}{*}{ Gender } & Male & 27.3 & 17.1 & 21.0 \\
\hline & Female & 31.5 & 16.7 & 20.8 \\
\hline & $\mathrm{P}$ & 0.001 & 0.4 & 0.7 \\
\hline \multirow{3}{*}{ Age } & $35 \leq$ & 30.5 & 17.2 & 19.9 \\
\hline & $<35$ & 28.2 & 16.3 & 22.7 \\
\hline & $\mathrm{P}$ & 0.003 & 0.04 & 0.001 \\
\hline \multirow{3}{*}{ Education } & Primary & 26.1 & 16.9 & 22.1 \\
\hline & University degree & 31.7 & 16.9 & 20.2 \\
\hline & $\mathrm{P}$ & 0.001 & 0.9 & 0.001 \\
\hline \multirow{3}{*}{ Marital status } & Single & 33.5 & 17.5 & 20.2 \\
\hline & Married & 27.5 & 16.5 & 21.3 \\
\hline & $\mathrm{P}$ & 0.001 & 0.03 & 0.04 \\
\hline \multirow{3}{*}{ Profession } & Physician & 35.8 & 16.6 & 24.0 \\
\hline & Non-physician & 27.9 & 15.1 & 20.5 \\
\hline & $\mathrm{P}$ & 0.001 & 0.15 & 0.003 \\
\hline \multirow{3}{*}{ Work setting } & Health centers & 29.2 & 16.2 & 20.1 \\
\hline & Hospital & 30.6 & 18.4 & 22.8 \\
\hline & $\mathrm{P}$ & 0.11 & 0.001 & 0.001 \\
\hline \multirow{3}{*}{ Work experience } & $10 \leq$ & 31.4 & 16.9 & 20.4 \\
\hline & $<10$ & 25.2 & 16.7 & 22.2 \\
\hline & $\mathrm{P}$ & 0.001 & 0.5 & 0.001 \\
\hline \multirow{3}{*}{ Employment type } & Permanent & 30.8 & 16.8 & 22.0 \\
\hline & Temporary & 28.9 & 16.9 & 20.3 \\
\hline & $\mathrm{P}$ & 0.007 & 0.7 & 0.001 \\
\hline
\end{tabular}

Logistic regression was used to determine the predictors of high burnout. An omnibus test was used to evaluate the regression model, which showed that the regression model had a suitable goodness of fit $(p<0.05)$. Our findings showed that five demographic variables, which included age, work experience, profession, type of employment, and marital status, were predictors of high burnout $(p<0.05)$. In other words, employees over the age of 35 years $(\mathrm{OR}=2.35)$, single individuals $(\mathrm{OR}=3.33)$, employees with less work experience $(\mathrm{OR}=9.09)$, physicians $(\mathrm{OR}=1.72)$, and employees with permanent employment $(\mathrm{OR}=5.0)$ were more likely to experience high levels of burnout (Table 5). 
Table 5. Logistic regression: Predictors of high burnout.

\begin{tabular}{|c|c|c|c|c|c|}
\hline \multicolumn{2}{|c|}{ Demographic Variables } & \multicolumn{2}{|c|}{ High Burnout } & \multirow{2}{*}{ OR } & \multirow{2}{*}{$\mathbf{P}$} \\
\hline & & $\mathbf{N}$ & $\%$ & & \\
\hline \multirow{2}{*}{ Gender } & Female & 177 & 59.2 & 1.58 & \multirow{2}{*}{0.06} \\
\hline & Male & 106 & 47.1 & ref & \\
\hline \multirow{2}{*}{ Age } & $35 \leq$ & 215 & 63.4 & 2.56 & \multirow{2}{*}{0.001} \\
\hline & $<35$ & 68 & 36.5 & ref & \\
\hline \multirow{2}{*}{ Education } & University degree & 224 & 67.4 & 2.04 & \multirow{2}{*}{0.07} \\
\hline & Primary & 59 & 30.7 & ref & \\
\hline \multirow{2}{*}{ Marital status } & Single & 136 & 72.3 & 3.33 & \multirow{2}{*}{0.001} \\
\hline & Married & 145 & 43.4 & ref & \\
\hline \multirow{2}{*}{ Profession } & Physician & 59 & 89.3 & 1.72 & \multirow{2}{*}{0.002} \\
\hline & Non-physician & 224 & 48.9 & ref & \\
\hline \multirow{2}{*}{ Work setting } & Hospital & 88 & 53.3 & 1.24 & \multirow{2}{*}{0.38} \\
\hline & Health centers & 195 & 54.3 & ref & \\
\hline \multirow{2}{*}{ Work experience } & $10 \leq$ & 255 & 68.1 & 9.09 & \multirow{2}{*}{0.001} \\
\hline & $<10$ & 28 & 18.7 & ref & \\
\hline \multirow{2}{*}{ Employment type } & Permanent & 132 & 64.1 & 5.0 & \multirow{2}{*}{0.001} \\
\hline & Temporary & 148 & 47.1 & ref & \\
\hline
\end{tabular}

\section{Discussion}

The aim of this study was to investigate the prevalence of burnout among PHC workers and its predictors. The findings showed that the prevalence of burnout was very high $(52.9 \%)$. The prevalence of high burnout has been reported at 17.3\% in Iran's PHC system [21], 2.6\% in health professionals of Ecuador [13], 7\% in Brazil's PHC staff [20], and 54\% in Iranian nurses [18]. In addition, findings of the review studies showed the prevalence of burnout in medical residents to be $35.7 \%$ [16], and among physicians it was $67 \%$ [6]. One possible reason for these differences in the prevalence rates is the differences in socio-economic status of the regions and participants. Also, differences in patient expectations can affect prevalence rates; as patients' expectations increase, the levels of stress and ultimately, burnout rise [13]. Organizational (e.g., organizational climate, management/leadership styles, and communication) and personal (e.g., demographic characteristics, individual attitudes, and personality) factors in health systems can also contribute to these differences [5,10,38]. In addition, the classification of the prevalence rates and the cut-off points for high levels of burnout were very different among various studies [37].

The percentage of high EE was higher in our study compared to others. This figure was 35.7\% in the Iranian PHC staff [21], 17.2\% in Ecuadorian health professionals [13], 43\% in Brazilian PHC staff [20], 64\% in Palestinian hospital emergency staff [4], and 32.7\% in Malawian health workers [23]. Also, the results of review studies showed the prevalence of EE was $20 \%-81 \%$ among Arab health workers [5], 31\% in nurses [17], 38.9\% in medical residents [16], and $72 \%$ in physicians [6]. The EE subscale mainly reflects aspects of the organizational environment such as role conflict, role ambiguity, participation in decision making, the reward system, and social support networks [35]. Therefore, employees who show a high degree of EE feel they cannot participate in decisions or lack social support and are generally not compatible with their organizational climate. The findings of a study among nurses reflected that a limited role in care planning had a positive effect on EE [39]. EE is associated with mental health problems and leads to anxiety and depression and ultimately, lower efficiency $[4,7]$. 
The prevalence of DP was very high in our study; this figure has been reported as $49.6 \%$ in Iran [21], 13.5\% in Ecuador [13], 17\% in Brazil [20], 38\% in Palestine [4], 22.8\% in Malawi [23], and $20 \%-80 \%$ in Arab countries. The findings of previous review studies indicate that the rate of high DP was $24 \%$ among nurses, $43.6 \%$ in medical residents, and $68 \%$ in physicians. DP represents the interpersonal dimension of burnout. The feeling of apathy towards patients due to too much contact with them and lack of adequate support from supervisors and colleagues can be the main reasons for DP. Findings of a study performed in Iran showed that leadership, lack of support, and poor relations with physicians had a positive effect on DP among nurses [39].

Based on the findings, we found that almost all employees experienced reduced PA. The rate of reduced PA in studies conducted in Iran [21,24,29], Ecuador [13], Brazil [20], Palestine [4], and Malawi [23] ranged from $8.8 \%$ to $34.6 \%$. In review studies, reduced PA was reported in $13 \%-86 \%$ of Arab health workers [5], 38\% of nurses [17], 34.3\% of medical residents [16], and $63.2 \%$ of physicians [6]. In general, PA scores in studies from the medical field have been significantly lower [17]. The feeling of reduced PA leads to reduced motivation, poor performance, and ultimately, reduced job satisfaction. Many PHC workers in Iran who work in rural health houses have no opportunities for promotion in their careers, leading to the feeling of lacking considerable occupational achievements.

Burnout was higher among young employees. The findings of previous studies confirm this point $[11,20,27,40]$. Maslach stated that this syndrome is more influential in young professionals who work in high-risk and client-centered fields such as health services [19], and as age increases burnout decreases. One possible reason may be the uncertain horizons and the lack of job security among young employees. In addition, older employees, over time, learn how to manage occupational stress and adapt and become resistant to burnout [4]

Single employees were exposed to about three times greater risk of burnout than married employees. In general, being single is an important risk factor for burnout $[19,40]$. Unmarried workers have less social and family support in professional issues [35]. Previous studies have suggested that family and social support have an inhibitory effect on burnout [17].

A high degree of burnout was more prevalent among less experienced employees. In previous studies, a similar finding was reported $[17,20]$. Experienced employees may feel more confident about their duties [13]. Also, having longer working experience is associated with a more advanced career and higher job satisfaction. Our findings also showed that personal achievements of experienced employees were greater.

Burnout among physicians was higher than in other professionals, which is in line with the findings of previous studies [5]. The prevalence of burnout among physicians was almost twice as high as that of general population in the United States [8]. A review study in France showed that the prevalence of burnout was $49 \%$ among physicians [15]. Studies conducted in recent years have reported that the rate of burnout among physicians was higher than 50\% [26]. This difference seems to be due to the great burden of responsibilities in the medical profession and the fact that these professionals have to make more critical decisions under conditions of uncertainty [13].

Although gender was not a predictor of high burnout, a higher percentage of female employees suffered from high burnout and emotional exhaustion. Perhaps this is because women often have a dual role, as both a health care provider and a mother, which can cause stress and depletion of overall energy [9].

This study had some limitations. Due to the cross-sectional nature of the study, strong causal relationships cannot be inferred. Future studies using longitudinal designs can help better understand the relationships between variables. Also, this study, like all others using self-report data, may be associated with social desirability bias and participants might have expressed their opinions too strongly or weakly. 


\section{Conclusions}

This study showed that burnout is a common problem among PHC workers. Overall, $52.9 \%$ of participants reported high levels of burnout. Less experienced, younger, and single employees and physicians were more at risk for high burnout. Further studies are needed to investigate this issue to develop effective interventions to reduce the level of burnout among employees. For employees at risk of burnout, preventive measures, such as strengthening social skills, communication competencies, coping strategies, and risk reduction factors are suggested. Improving job satisfaction through rewards, incentives, career development, and educational opportunities can lead to an increase in the sense of personal achievement. Depersonalization can be reduced through employee involvement, role resolution, and support from supervisors and colleagues.

Author Contributions: E.Z. contributed to the literature review, the conceptualization and writing of the original article and prepared the first draft. All the authors contributed equally to the research design, data analysis, revision and approved the final manuscript.

Conflicts of Interest: The authors declare no conflict of interest.

\section{References}

1. Dugani, S.; Afari, H.; Hirschhorn, L.R.; Ratcliffe, H.; Veillard, J.; Martin, G.; Lagomarsino, G.; Basu, L.; Bitton, A. Prevalence and factors associated with burnout among frontline primary health care providers in low-and middle-income countries: A systematic review. Gates Open Res. 2018, 2, 4. [CrossRef] [PubMed]

2. Danaei, G.; Farzadfar, F.; Kelishadi, R.; Rashidian, A.; Rouhani, O.M.; Ahmadnia, S.; Ahmadvand, A.; Arabi, M.; Ardalan, A.; Arhami, M.; et al. Iran in transition. Lancet 2019, 393, 1984-2005. [CrossRef]

3. Parola, V.; Coelho, A.; Cardoso, D.; Sandgren, A.; Apóstolo, J. Prevalence of burnout in health professionals working in palliative care: A systematic review. JBI Database Syst. Rev. Implement. Rep. 2017, 15, 1905-1933. [CrossRef] [PubMed]

4. Hamdan, M. Burnout among workers in emergency Departments in Palestinian hospitals: Prevalence and associated factors. BMC Health Serv. Res. 2017, 17, 407. [CrossRef] [PubMed]

5. Elbarazi, I.; Loney, T.; Yousef, S.; Elias, A. Prevalence of and factors associated with burnout among health care professionals in Arab countries: A systematic review. BMC Health Serv. Res. 2017, 17, 491. [CrossRef]

6. Rotenstein, L.S.; Torre, M.; Ramos, M.A.; Rosales, R.C.; Guille, C.; Sen, S.; Mata, D.A. Prevalence of burnout among physicians: A systematic review. JAMA 2018, 320, 1131-1150. [CrossRef] [PubMed]

7. Sofology, M.; Efstratopoulou, M.; Dunn, T. Predicting burnout syndrome in Greek mental health professionals. J. Soc. Serv. Res. 2019, 45, 142-149. [CrossRef]

8. Dyrbye, L.N.; Shanafelt, T.D.; Sinsky, C.A.; Cipriano, P.F.; Bhatt, J.; Ommaya, A.; West, C.P.; Meyers, D. Burnout among Health Care Professionals: A Call to Explore and Address This Underrecognized Threat to Safe, High-Quality Care; NAM (National Academy of Medicine) Perspective; Discussion Paper, National Academy of Medicine: Washington, DC, USA, 2017.

9. García-Izquierdo, M.; Ríos-Rísquez, M.I. The relationship between psychosocial job stress and burnout in emergency departments: An exploratory study. Nurs. Outlook 2012, 60, 322-329. [CrossRef] [PubMed]

10. Rezaei, S.; Karami Matin, B.; Hajizadeh, M.; Soroush, A.; Nouri, B. Prevalence of burnout among nurses in Iran: A systematic review and meta-analysis. Int. Nurs. Rev. 2018, 65, 361-369. [CrossRef]

11. Bartosiewicz, A.; Januszewicz, P. Readiness of Polish Nurses for Prescribing and the Level of Professional Burnout. Int. J. Environ. Res. Public Health 2019, 16, 35. [CrossRef]

12. McCormack, H.M.; MacIntyre, T.E.; O'Shea, D.; Herring, M.P.; Campbell, M.J. The Prevalence and Cause (s) of Burnout among Applied Psychologists: A Systematic Review. Front. Psychol. 2018, 9, 1897. [CrossRef] [PubMed]

13. Ramírez, M.R.; Otero, P.; Blanco, V.; Ontaneda, M.P.; Díaz, O.; Vázquez, F.L. Prevalence and correlates of burnout in health professionals in Ecuador. Compr. Psychiatry 2018, 82, 73-83. [CrossRef] [PubMed]

14. Pavlakis, A.; Raftopoulos, V.; Theodorou, M. Burnout syndrome in Cypriot physiotherapists: A national survey. BMC Health Serv. Res. 2010, 10, 63. [CrossRef] [PubMed]

15. Kansoun, Z.; Boyer, L.; Hodgkinson, M.; Villes, V.; Lançon, C.; Fond, G. Burnout in French physicians: A systematic review and meta-analysis. J. Affect. Disord. 2019, 246, 132-147. [CrossRef] [PubMed] 
16. Rodrigues, H.; Cobucci, R.; Oliveira, A.; Cabral, J.V.; Medeiros, L.; Gurgel, K.; Souza, T.; Gonçalves, A.K. Burnout syndrome among medical residents: A systematic review and meta-analysis. PLoS ONE 2018, 13, e0206840. [CrossRef] [PubMed]

17. Molina-Praena, J.; Ramirez-Baena, L.; Gómez-Urquiza, J.; Cañadas, G.; De la Fuente, E. Levels of burnout and risk factors in medical área nurses: A meta-analytic study. Int. J. Environ. Res. Public Health 2018, 15, 2800. [CrossRef]

18. Khammar, A.; Dalvand, S.; Hashemian, A.H.; Poursadeghiyan, M.; Yarmohammadi, S.; Babakhani, J.; Yarmohammadi, H. Data for the prevalence of nurses' burnout in Iran (a meta-analysis dataset). Data Brief 2018, 20, 1779-1786. [CrossRef]

19. Corrado, B.; Ciardi, G.; Fortunato, L.; Iammarrone, C.S. Burnout syndrome among Italian physiotherapists: A cross-sectional study. Eur. J. Physiother. 2018. [CrossRef]

20. Silva, S.C.P.S.; Nunes, M.A.P.; Santana, V.R.; Reis, F.P.; Machado Neto, J.; Lima, S.O. Burnout syndrome in professionals of the primary healthcare network in Aracaju, Brazil. Ciênc. Saúde Coletiva 2015, 20, 3011-3020. [CrossRef]

21. Amiri, M.; Khosravi, A.; Eghtesadi, A.R.; Sadeghi, Z.; Abedi, G.; Ranjbar, M.; Mehrabian, F. Burnout and its influencing factors among primary health care providers in the North East of Iran. PLoS ONE 2016, 11, e0167648. [CrossRef]

22. Bawakid, K.; Abdulrashid, O.; Mandoura, N.; Shah, H.B.U.; Ibrahim, A.; Akkad, N.M.; Mufti, F. Burnout of Physicians Working in Primary Health Care Centers under Ministry of Health Jeddah, Saudi Arabia. Cureus 2017, 9, e1877. [CrossRef] [PubMed]

23. Thorsen, V.C.; Tharp, A.L.T.; Meguid, T. High rates of burnout among maternal health staff at a referral hospital in Malawi: A cross-sectional study. BMC Nurs. 2011, 10, 9. [CrossRef] [PubMed]

24. Bijari, B.; Abassi, A. Prevalence of burnout syndrome and associated factors among rural health workers (Behvarzes) in South Khorasan. Iran. Red Crescent Med. J. 2016, 18, e25390. [CrossRef] [PubMed]

25. Wiederhold, B.K.; Cipresso, P.; Pizzioli, D.; Wiederhold, M.; Riva, G. Intervention for physician burnout: A systematic review. Open Med. 2018, 13, 253-263. [CrossRef] [PubMed]

26. West, C.P.; Dyrbye, L.N.; Shanafelt, T.D. Physician burnout: Contributors, consequences and solutions. J. Intern. Med. 2018, 283, 516-529. [CrossRef] [PubMed]

27. Amoafo, E.; Hanbali, N.; Patel, A.; Singh, P. What are the significant factors associated with burnout in doctors? Occup. Med. 2014, 65, 117-121. [CrossRef] [PubMed]

28. Jurado, M.D.M.M.; del Carmen Pérez-Fuentes, M.; Linares, J.J.G.; Martín, A.B.B. Burnout in Health Professionals According to Their Self-Esteem, Social Support and Empathy Profile. Front. Psychol. 2018, 9, 424. [CrossRef]

29. Malakouti, S.K.; Nojomi, M.; Salehi, M.; Bijari, B. Job stress and burnout syndrome in a sample of rural health workers, behvarzes, in Tehran, Iran. Iran. J. Psychiatry 2011, 6, 70-74.

30. Nekoei Moghadam, M.; Amiresmaili, M.; Sadeghi, V.; Zeinalzadeh, A.H.; Tupchi, M.; Parva, S. A qualitative study on human resources for primary health care in Iran. Int. J. Health Plan. Manag. 2018, 33, e38-e48. [CrossRef]

31. Navidian, A.; Navaee, M.; Kaykha, H. Effectiveness of stress inoculation training on occupational stress of midwives in healthcare centers of Zahedan in Health Transformation Plan in 2017. J. Educ. Health Promot. 2019, 8, 66 .

32. Abedi, G.; Kontai, S.; Amir, S.; Marvi, A.; Mazidi, S.; Abedini, E.; Abbasi Chaleshtary, A. SWOT Analysis of Health Reform Plan on Healthcare Sector from the Stakeholder Perspective. J. Mazandaran Univ. Med. Sci. 2018, 28, 199-212.

33. Peikanpour, M.; Esmaeli, S.; Yousefi, N.; Aryaeinezhad, A.; Rasekh, H. A review of achievements and challenges of Iran's health transformation plan. Payesh 2018, 17, 481-494. [CrossRef]

34. Ghanbari, A.; Moaddab, F.; Heydarzade, A.; Jafaraghaee, F.; Barari, F. Health System Evolution Plan; a New Approach to Health Care Delivery: The Challenge Ahead. Hakim Health Syst. Res. 2017, 20, 1-8.

35. El-Ibiary, S.Y.; Yam, L.; Lee, K.C. Assessment of burnout and associated risk factors among pharmacy practice faculty in the United States. Am. J. Pharm. Educ. 2017, 81, 75. [PubMed]

36. Brenninkmeijer, V.; VanYperen, N. How to conduct research on burnout: Advantages and disadvantages of a unidimensional approach in burnout research. Occup. Environ. Med. 2003, 60, i16-i20. [CrossRef] [PubMed] 
37. Doulougeri, K.; Georganta, K.; Montgomery, A. “Diagnosing” burnout among healthcare professionals: Can we find consensus? Cogent Med. 2016, 3, 1237605. [CrossRef]

38. Arab, M.; Tajvar, M.; Akbari, F. Selection an appropriate leadership style to direct hospital manpower. Iran. J. Public Health 2006, 35, 64-69.

39. Arab, M.; Rahimi, A.; Vali, L.; Ravangard, R.; Akbari Sari, A. Study of the relationship between nurses' work environment indices and their burnout aspects in TUMS teaching hospitals. Iran Occup. Health 2012, 9, $39-51$.

40. Tijdink, J.K.; Vergouwen, A.C.; Smulders, Y.M. Emotional exhaustion and burnout among medical professors; a nationwide survey. BMC Med. Educ. 2014, 14, 183. [CrossRef]

(C) 2019 by the authors. Licensee MDPI, Basel, Switzerland. This article is an open access article distributed under the terms and conditions of the Creative Commons Attribution (CC BY) license (http://creativecommons.org/licenses/by/4.0/). 